\title{
Using droplet-based microfluidics to improve the catalytic properties of RNA under multiple-turnover conditions
}

\author{
MICHAEL RYCKELYNCK, ${ }^{1,2}$ STÉPHANIE BAUDREY, ${ }^{1}$ CHRISTIAN RICK, ${ }^{1,2}$ ANNICK MARIN, ${ }^{2}$ \\ FAITH COLDREN, ${ }^{2}$ ERIC WESTHOF, ${ }^{1}$ and ANDREW D. GRIFFITHS ${ }^{2,3}$ \\ ${ }^{1}$ Architecture et Réactivité de I'ARN, CNRS UPR 9002, Université de Strasbourg, 67084 Strasbourg, France \\ ${ }^{2}$ Institut de Science et d'Ingénierie Supramoléculaires (ISIS), CNRS UMR 7006, Université de Strasbourg, 67083 Strasbourg, France \\ ${ }^{3}$ Ecole Supérieure de Physique et de Chimie Industrielles de la Ville de Paris (ESPCI ParisTech), CNRS UMR 8231, 75231 Paris, France
}

\begin{abstract}
In vitro evolution methodologies are powerful approaches to identify RNA with new functionalities. While Systematic Evolution of Ligands by Exponential enrichment (SELEX) is an efficient approach to generate new RNA aptamers, it is less suited for the isolation of efficient ribozymes as it does not select directly for the catalysis. In vitro compartmentalization (IVC) in aqueous droplets in emulsions allows catalytic RNAs to be selected under multiple-turnover conditions but suffers severe limitations that can be overcome using the droplet-based microfluidics workflow described in this paper. Using microfluidics, millions of genes in a library can be individually compartmentalized in highly monodisperse aqueous droplets and serial operations performed on them. This allows the different steps of the evolution process (gene amplification, transcription, and phenotypic assay) to be uncoupled, making the method highly flexible, applicable to the selection and evolution of a variety of RNAs, and easily adaptable for evolution of DNA or proteins. To demonstrate the method, we performed cycles of random mutagenesis and selection to evolve the X-motif, a ribozyme which, like many ribozymes selected using SELEX, has limited multiple-turnover activity. This led to the selection of variants, likely to be the optimal ribozymes that can be generated using point mutagenesis alone, with a turnover number under multiple-turnover conditions, $k_{\text {cat, }}^{\text {ss }} \sim 28$-fold higher than the original X-motif, primarily due to an increase in the rate of product release, the rate-limiting step in the multiple-turnover reaction.
\end{abstract}

Keywords: in vitro evolution; RNA; ribozymes; high-throughput screening; droplet-based microfluidics

\section{INTRODUCTION}

In vitro evolution methodologies are powerful approaches to identify RNA with new functionalities to study the origin of life or develop new molecular tools (Romero-Lopez et al. 2007; Ellington et al. 2009). Among them, Systematic Evolution of Ligand by Exponential enrichment (SELEX) (Ellington and Szostak 1990; Tuerk and Gold 1990) is the most widely used strategy and has proved to be an extremely effective method for the selection of highly specific RNA (and DNA) aptamers binding a wide range of ligands with high affinity (Stoltenburg et al. 2007). In addition, SELEX has been used extensively to isolate catalytic RNAs (ribozymes) with a wide range of activities, many of which would have been relevant in the RNA World (Bartel and Unrau 1999). However, it is likely that these ribozymes are not optimal and can be further improved since SELEX is not a true selection for catalysis. Catalytic RNAs are typically selected using a variant of

Corresponding authors: andrew.griffiths@espci.fr, m.ryckelynck@ unistra.fr

Article published online ahead of print. Article and publication date are at http://www.rnajournal.org/cgi/doi/10.1261/rna.048033.114. Freely available online through the RNA Open Access option. the original SELEX procedure which relies on the self-modification of the RNA, or of a substrate attached to it, followed by the selective enrichment of modified RNAs or RNAs attached to the product (Bartel and Szostak 1993). Therefore, the selection is for single-turnover intramolecular (in cis) reactions, or for a limited number of turnovers in the case of polymerases (Johnston et al. 2001; Lawrence and Bartel 2005), and there is selection neither for conversion of untethered substrates (in trans reaction), nor for multiple turnover (or high $k_{\text {cat }}$ ) which likely precludes the selection of highly efficient ribozymes (Griffiths and Tawfik 2000).

In vitro compartmentalization (IVC), in which genes in a library are individually compartmentalized and expressed in water droplets in an emulsion (Tawfik and Griffiths 1998), is an attractive alternative to SELEX. IVC allows the selection of ribozymes (or protein enzymes) acting on multiple substrate molecules free in solution (in trans reaction) and, therefore, allows direct selection for intermolecular catalysis. This approach has, for example, been used to select ribozymes that

(C) 2015 Ryckelynck et al. This article, published in RNA, is available under a Creative Commons License (Attribution-NonCommercial 4.0 International), as described at http://creativecommons.org/licenses/by-nc/4.0/. 
catalyze multiple-turnover Diels-Alder cycloadditions (Agresti et al. 2005) and the first RNA polymerase ribozyme capable of catalyzing the synthesis of another ribozyme (Wochner et al. 2011). However, precise, quantitative experiments using IVC are difficult due to the relatively high polydispersity of the droplets and the biological variance that can arise from single gene expression (Griffiths and Tawfik 2006). Furthermore, it is difficult to add new reagents to droplets once they are formed, requiring gene expression and measurement of enzyme activity to be performed simultaneously and under the same conditions.

These limitations can be overcome by using droplet-based microfluidics. Using microfluidic systems it is simple to generate highly monodisperse droplets (Anna et al. 2003) but also to individually fuse (Chabert et al. 2005), inject (Abate et al. 2010), split (Link et al. 2004), or sort them based on their fluorescence (Baret et al. 2009). The use of several successive microfluidic modules allows serial operations to be performed on droplets at kilohertz frequencies (Guo et al. 2012). For instance, using only two modules (a droplet generator and a fuser), it was possible to compartmentalize and amplify single $\beta$-galactosidase-coding genes in a first set of droplets. These droplets were then paired and fused with droplets containing an in vitro transcription/translation system and a fluorogenic substrate allowing the amplified genes to be simultaneously expressed and $\beta$-galactosidase activity measured (Mazutis et al. 2009a). The addition of a fluorescence-activated electrocoalescence module (Fidalgo et al. 2008) at the end of the previous workflow enabled efficient enrichment of the $\beta$-galactosidase-coding gene from a mutated gene encoding an inactive variant based on catalytic activity of the encoded enzyme using a completely in vitro system (Fallah-Araghi et al. 2012). However, in this system, gene expression and the activity assay were still performed simultaneously, and the in vitro evolution of an enzyme using this technology has still to be demonstrated.

Here, we upgraded our previous microfluidic workflow (Fallah-Araghi et al. 2012) by adding a fourth microfluidic module (a picoinjector) which allowed gene expression to be uncoupled from the activity assay, and used it to evolve the X-motif nuclease ribozyme under multiple-turnover conditions.

The X-motif ribozyme was found to be the dominant species isolated after in vitro evolution of self-cleaving RNA using SELEX and is one of the most active self-cleaving ribozymes discovered to date (Tang and Breaker 2000). However, once converted into a bimolecular system the efficiency of the reaction was reduced from $k_{\mathrm{obs}}=0.7 \mathrm{~min}^{-1}$ in cis to $k_{\mathrm{obs}}=0.2 \mathrm{~min}^{-1}$ in trans, when assayed in single-turnover conditions (Lazarev et al. 2003). It has, however, been proposed that the X-motif should theoretically be able to evolve to catalyze RNA cleavage at rates at least equivalent to the protein enzyme Ribonuclease A under single-turnover conditions $\left(k_{\mathrm{cat}} \sim 80,000 \mathrm{~min}^{-1}\right)$ (Emilsson et al. 2003). This well-studied ribozyme is, therefore, an attractive model for the evolution of efficient trans acting ribozymes under multiple-turnover conditions using droplet-based microfluidic systems.

The use of the microfluidic system to select for the in trans reaction under multiple-turnover conditions led to the isolation of optimal variants having a turnover number for the in trans reaction under multiple-turnover conditions, $k_{\text {cat }}^{\text {ss }}$, $\sim 28$-times higher than that of the original ribozyme. The characterization of these improved X-motifs revealed that most of the mutations were located in the substrate-binding site and that they primarily act by favoring product release, the rate-limiting step in the reaction catalyzed by the original X-motif.

\section{RESULTS}

\section{X-motif activity under multiple-turnover conditions}

We first evaluated the catalytic performances of the X-motif under multiple-turnover conditions by incubating the ribozyme with a molar excess of fluorogenic RNA substrate labeled with a fluorophore (Atto 488) and a quencher (BHQ 1) at its $5^{\prime}$ and $3^{\prime}$ end, respectively (Fig. 1B). Upon substrate cleavage and the release of at least one of the reaction products, fluorescence is emitted allowing nuclease activity to be monitored (Fig. 1C). Burst kinetics were observed, characterized by a presteady state during which the reaction rate decreased exponentially before reaching a steady state with constant reaction rate (Fig. 1C, inset). The observation of burst kinetics indicated that the rate-limiting step of the reaction is product release (Hartley and Kilby 1954), as reported for a number of other nuclease ribozymes (Herschlag and Cech 1990a,b; Young et al. 1991; Stage-Zimmermann and Uhlenbeck 1998; Shih and Been 2000; Hsieh et al. 2009). The apparent $k_{\text {cat }}$ during the presteady state $\left(k_{\text {burst }}=0.36 \pm\right.$ $\left.0.04 \mathrm{~min}^{-1}\right)$, calculated from the burst phase, was close to that previously measured with radiolabeled substrates under single-turnover conditions $\left(k_{\mathrm{obs}}=0.2 \mathrm{~min}^{-1}\right)$ (Lazarev et al. 2003) but the turnover number in the steady state $\left(k_{\text {cat }}^{\text {ss }}\right)$, was $\sim 20$-fold lower (Table 1).

To isolate optimized variants, we prepared a gene library by error-prone PCR (1.6 mutations per gene on average) using as template a gene coding for an extended form of the $\mathrm{X}$ motif (Fig. 1A) bearing a constant region at the $3^{\prime}$ end to allow gene amplification and a purine-rich constant region at the $5^{\prime}$ end to ensure optimal and homogeneous transcription initiation. While burst kinetics was still observed with the extended ribozyme, the fraction of active molecules (calculated from the amplitude of the burst) increased. The addition of the constant regions also increased the dissociation constant $\left(K_{\mathrm{d}}\right)$ of the ribozyme-substrate complex by 6.6-fold and decreased $k_{\text {burst }}$ by $25 \%$ revealing a possible interference with substrate recognition (Table 1). Interestingly, the $k_{\text {cat }}^{\text {ss }}$ of the extended X-motif increased 4.0-fold. 


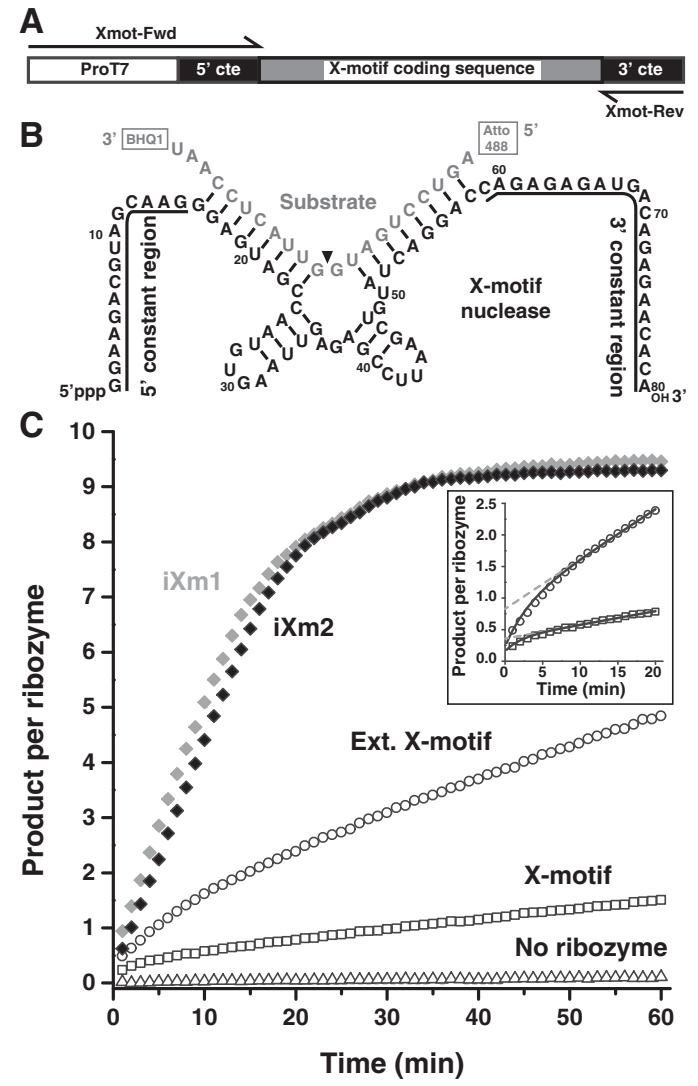

FIGURE 1. Structure and activity of the original X-motif and its extended form. (A) Organization of extended X-motif coding gene. The extended X-motif coding sequence was placed under the control of a T7 RNA polymerase promoter (ProT7). Annealing sites of amplification primers (Xmot-Fwd and Xmot-Rev) are represented by arrows. (B) Secondary structure model. The catalytic core of the X-motif nuclease is shown as proposed previously (Lazarev et al. 2003). The constant regions appended to both ends of the extended ribozyme are underlined. The nuclease is shown in complex with its fluorogenic substrate (in gray) and the cutting site is indicated (black triangle). Before the reaction occurs, the fluorescence of Atto 488 (ex. $488 \mathrm{~nm} / \mathrm{em} .525 \mathrm{~nm}$ ) is quenched by the BHQ1 quencher (Abs. $480-580 \mathrm{~nm}$ ). Upon cleavage, a fluorescent product is released and signal is observed. $(C)$ Ribozyme activity assay. X-motif (open squares), its extended form (open circles), iXm1 (gray diamonds), and iXm2 (black diamonds) were incubated with a 10 -fold molar excess of fluorogenic substrate at $37^{\circ} \mathrm{C}$ and the fluorescence monitored with time. A burst phase was observed during the first 20 min (inset) of the reactions catalyzed by X-motif (open squares) and its extended form (open circles), but not for the evolved variants iXms. Burst phase kinetics was fitted to the burst equation (Wanninayake and Walker 2012). The fit is shown in black and the extrapolation of the linear phase to $t_{0}$ is shown as a gray dashed line. This allowed determination of $k_{\mathrm{burst}}, k_{\mathrm{cat}}^{\mathrm{ss}}$ and the fraction of active X-motif and extended Xmotif reported in Table 1 . The $k_{\text {cat }}^{\text {ss }}$ for the evolved ribozymes iXm1 and $\mathrm{iXm} 2$ were calculated from a linear fit to the initial rate. The reaction without ribozyme is also shown (open triangles).

\section{Selection strategy}

A workflow based on four microfluidic chips was used to screen the library for improved variants (Fig. 2A). First, DNA molecules were compartmentalized in highly monodisperse $(\mathrm{CV} \leq 3 \%) 2.5 \mathrm{pL}$ droplets (produced at $\sim 12,000$ droplets/sec) together with PCR reagents and EvaGreen DNA intercalating dye (Fig. 2B,F). The aqueous phase was dispersed in fluorinated oil supplemented with 3\% fluorosurfactant, the emulsion was collected off-chip and thermocycled. The fraction of droplets initially containing more than one DNA was limited to $\leq 2 \%$ by using limiting dilution of DNA to give an average number $(\lambda)$ of $\leq 0.2$ DNA molecules per droplet, as in digital PCR (Kiss et al. 2008). The presence of EvaGreen in the PCR reaction allowed droplets containing amplified DNA to be identified and $\lambda$ to be measured $(\leq 0.2$, Table 2$)$.

After thermocycling, the $2.5 \mathrm{pL}$ droplets were reinjected into a second microfluidic device (Fig. 2C), paired with $16 \mathrm{pL}$ droplets containing an in vitro transcription (IVT) mixture generated on-chip at $\sim 2000$ droplets/sec and pairs of droplets were coalesced using an electric field (Chabert et al. 2005). Different concentrations of Texas Red (orange fluorescence) were included in the PCR and IVT droplets to distinguish them (Fig. 2G), to determine the fusion efficiency $(\sim 80 \% \pm 5 \%$, Table 2$)$ and to measure the emulsion dispersity $(\mathrm{CV} \leq 10 \%)$. The emulsion was collected offchip and incubated to allow gene transcription to occur.

The RNA-containing droplets were reinjected $(\sim 2000$ droplets/sec) into a picoinjection device (Abate et al. 2010) and $4 \mathrm{pL}$ of a solution containing $1 \mathrm{M} \mathrm{NaCl}$ to inactive the T7 RNA polymerase and stop transcription, $20 \mu \mathrm{M}$ of the fluorogenic substrate plus a fluorescent blue dye to measure the amount of substrate delivered to the droplet and, when necessary, a variable amount of a nonfluorogenic substrate, was accurately injected (CV $\leq 15 \%)$ into each $18 \mathrm{pL}$ droplet (Fig. 2D, $\mathrm{H})$. The concentration of substrate was $4 \mu \mathrm{M}, 20$-fold higher than the concentration of ribozyme $(0.2 \mu \mathrm{M})$ measured by RT-qPCR and 1000-fold higher than the $K_{\mathrm{d}}$ (and $K_{\mathrm{M}}$ ), ensuring that the ribozymes were selected for $k_{\text {cat }}$ (rather than $k_{\text {cat }} /$ $K_{\mathrm{M}}$ ) under multiple-turnover conditions. We found that T7 RNA polymerase interfered with the fluorogenic assay via an unknown mechanism, generating high background fluorescence (Supplemental Fig. S1). However, supplementing the injected solution with $1 \mathrm{M} \mathrm{NaCl}$ was found to prevent this effect.

After a last off-chip incubation, droplets were reinjected into a fluorescence-activated droplet-sorting device (Baret et al. 2009) and their fluorescence analyzed. Droplets were detected by their orange fluorescence and sorted based on blue (concentration of picoinjected substrate) and green (concentration of product) fluorescence. The $1 \%$ most green fluorescent droplets were gated and sorted (Table 2; Fig. 2E,I).

Finally, sorted droplets were broken, the DNA recovered, amplified by PCR and used as template for mutagenesis or directly used to start a new round of selection.

\section{Selection of improved variants}

We first validated the screening method by performing a selection on a simple model library made of a mixture (1/49) of 
TABLE 1. Kinetic parameters, substrate affinity, and product inhibition of ribozymes

\begin{tabular}{|c|c|c|c|c|c|c|}
\hline Variant & $\begin{array}{c}k_{\text {burst }} \\
\left(\min ^{-1}\right)\end{array}$ & $\begin{array}{c}k_{\mathrm{cat}}^{\mathrm{ss}} \\
\left(\min ^{-1}\right)\end{array}$ & $\begin{array}{l}\text { Ribozyme active } \\
\text { fraction }^{\mathrm{a}}\end{array}$ & $\begin{array}{l}K_{\mathrm{d}} \text { for substrate } \\
(\mathrm{nM})\end{array}$ & $\begin{array}{c}K_{\mathrm{M}} \text { for substrate } \\
(\mathrm{nM})\end{array}$ & $\begin{array}{c}\mathrm{IC}_{50} \text { of products } \\
(\mu \mathrm{M})\end{array}$ \\
\hline X-motif & $0.36 \pm 0.04$ & $0.017 \pm 0.001$ & $36 \% \pm 3 \%$ & $6.5 \pm 0.2$ & n.d. & $3.2 \pm 0.7$ \\
\hline Ext. X-motif & $0.27 \pm 0.02$ & $0.07 \pm 0.005$ & $85 \% \pm 5 \%$ & $42.9 \pm 6.8$ & n.d. & $4.7 \pm 0.7$ \\
\hline iXm1 & n.d. & $0.48 \pm 0.01$ & n.d. & $>1000$ & $1680 \pm 120$ & $10.1 \pm 0.9$ \\
\hline iXm2 & n.d. & $0.48 \pm 0.04$ & n.d. & $>1000$ & $1910 \pm 210$ & $12.9 \pm 1.6$ \\
\hline
\end{tabular}

genes coding for the extended X-motif ribozyme and an inactive RNA (Fig. 3A). A single round of selection resulted in a 28 -fold enrichment for extended X-motif-coding genes (Fig. 3B) and a consistent 26-fold increase in nuclease activity in the selected sample (Fig. 3C), demonstrating the success of the selection.

The procedure was next applied to the library generated from the extended X-motif. During the first two rounds of selection no nonfluorogenic substrate was added (rounds 1 and 2 in Fig. 4A). In subsequent rounds the picoinjected mixture was supplemented with increasing amounts of nonfluorogenic substrate to progressively increase the selection pressure for multiple-turnover. New rounds of mutagenesis were performed after rounds 2, 4, and 6 of selection (red arrows in Fig. $4 \mathrm{~A})$ to maintain genetic diversity in the libraries. This strategy resulted in a rapid increase in the $k_{\text {cat }}^{\text {ss }}$ of the libraries over the first four rounds of selection but no further significant improvement was observed over the five subsequent rounds of selection. Performing the experiment at a lower mutation rate ( 0.8 mutations per gene) also led to improvement but at a lower rate, and the plateau value was not reached after eight rounds of selection (Supplemental Fig. S2), indicating that the rate of evolution is modulated by the mutation rate.

\section{Characterization of selected variants}

Libraries obtained after rounds 2, 3, 6, and 9 of selection were cloned, 20 variants from each library were sequenced and their activity was assayed. Over $75 \%$ of the cloned ribozymes had a higher $k_{\text {cat }}^{\text {ss }}$ than the original extended X-motif and, as the number of rounds of mutation and selection increased, increasingly efficient catalysts appeared (Fig. 4B; Supplemental Tables S1-S4). A pool of inactive RNAs, and RNAs with lower $k_{\text {cat }}^{\text {ss }}$ than the original extended X-motif was found to survive the selection process. These RNAs can survive selection for two reasons. First, an inefficient RNA can be cocompartmentalized with an efficient RNA and the droplet containing both RNAs selected; as the distribution of RNAs in droplets follows a Poisson distribution with $\lambda \approx 0.2$, $\sim 9.67 \%$ of droplets containing an efficient RNA will also contain at least one additional RNA (Baret et al. 2009). Second, sorting errors can occur, mainly due to small PCR droplets that escaped the fusion process. While these two sources of errors did not greatly impact the selection process, the fraction of false positive variants could potentially be reduced further by decreasing $\lambda$, at the expense of the number of molecules analyzed (Baret et al. 2009), and by using a hydrodynamic droplet size-sorting device to remove unfused PCR droplets after droplet fusion (Mazutis and Griffiths 2009).

Sequence analysis revealed that several mutations contributed to the improvement in activity and that most of them were embedded in the substrate recognition site of the ribozyme (Fig. 4D; Supplemental Tables S1-S4). With increasing rounds of mutations and selection, the mutation density (average number of mutations), $\mu$, in the substrate-binding site increased (Fig. 4C). Interestingly, in early rounds of selection mutations were distributed quite widely across the substratebinding site. However, in the later rounds of selection there was a tendency for the mutations to be concentrated at the outer extremities of the substrate-binding site, with few mutations being found elsewhere in the substrate-binding site (Fig. 4C; Supplemental Tables S1-S4). This might be explained by single point mutations more toward the center of the substrate-binding site that appear early in selection being less advantageous than combinations of mutations at the extremities of the substrate-binding site that arise in later rounds.

G17A appeared in early steps and was found in all improved molecules analyzed after the last round of selection. A57G rapidly emerged too, but was limited to a subset of the population and was frequently found in the same molecules as C58A/U. Interestingly, these two mutations were never found associated, at least in the sample analyzed, with the positive mutation $\mathrm{C} 53 \mathrm{U}$ and appeared to be, together with G17A, the most frequent combination observed in the variants sequenced in the last round of selection. In addition, secondary mutations A18C and G55U were found associated with the most active variants. Besides these mutations in the substrate-binding site, G30A, which emerged late, was found in the first loop of the ribozyme, a region found to be variable in a previous study (Lazarev et al. 2003).

In addition, one can observe that mutations maintaining the structure of the molecule (e.g., A32G and U27C) tend to appear in the stem 1 while the process progressed (Supplemental Tables S1-S4).

To better define the contribution of each mutation identified above, molecules carrying either single or multiple point mutations were produced and their activity tested (Fig. 5). The single point mutation having the highest effect on 
A

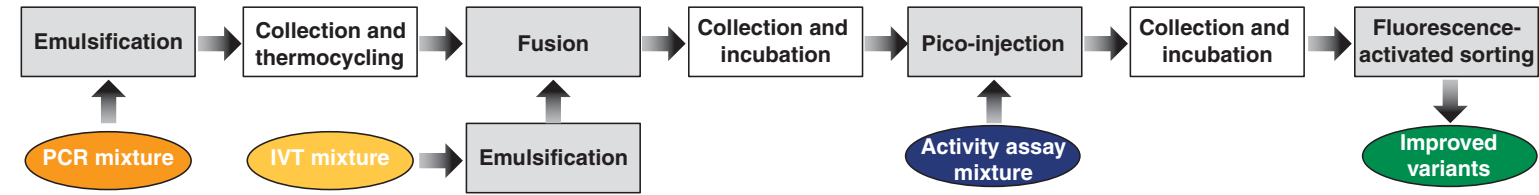

B
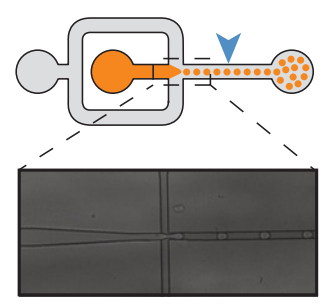

F

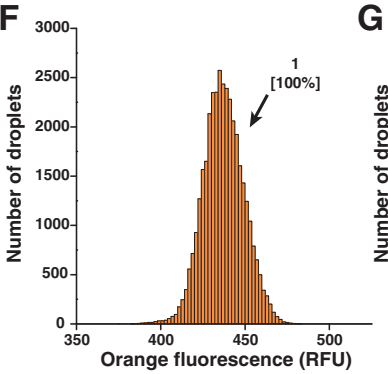

G
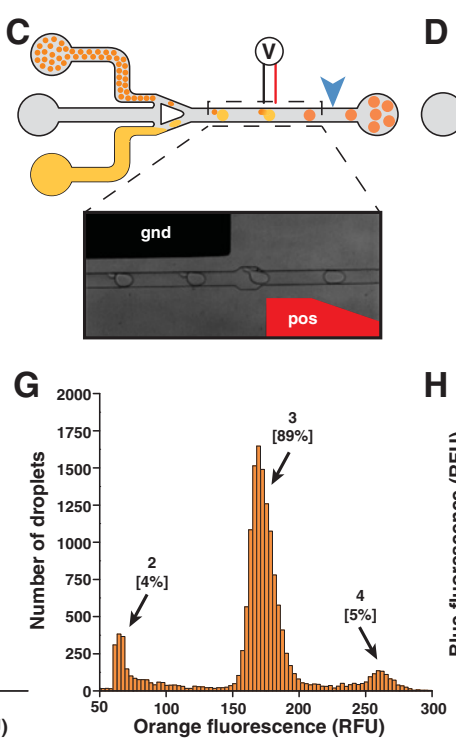

D

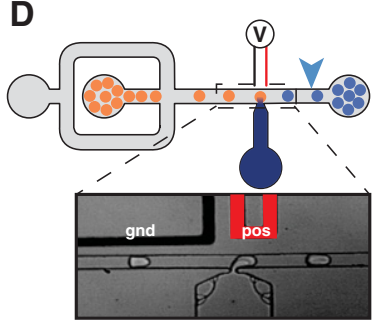

E
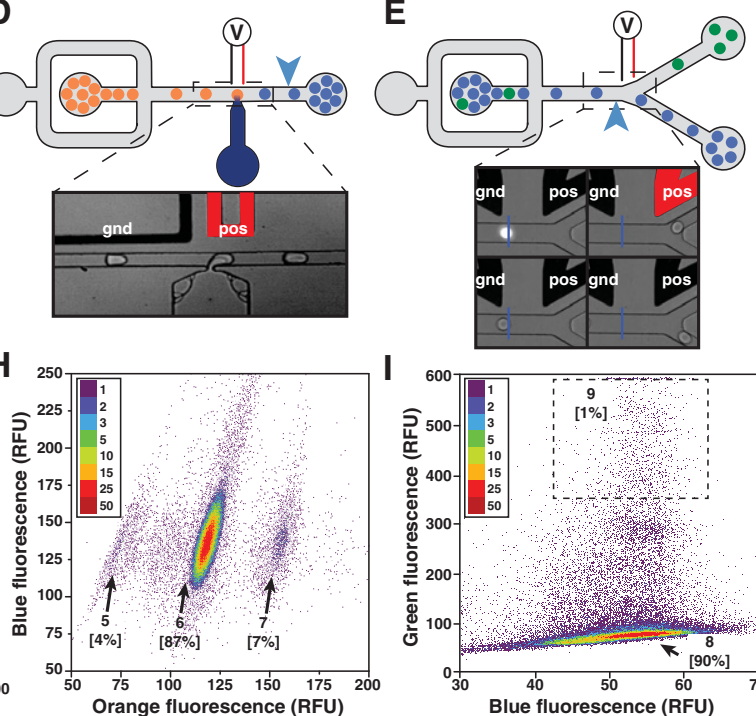

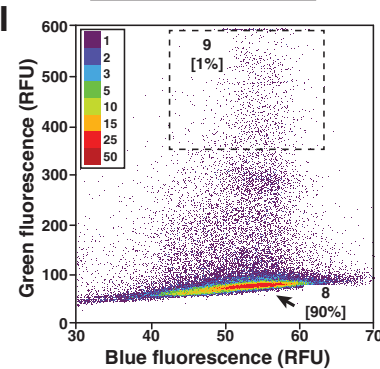

FIGURE 2. Droplet-based microfluidic selection strategy. (A) Droplet-based microfluidic workflow. Gray and white boxes distinguish on-chip from off-chip steps, respectively. (B-I) A typical selection is depicted and the analysis profiles corresponding to subsets of $15,000(F, G)$ or $65,000(H, I)$ droplets are shown. A gene library was diluted in PCR reagents to give an average, $\lambda$, of 0.2 DNA molecules per droplet. The mixture was injected into a droplet generator $(B)$ and compartmentalized in $2.5 \mathrm{pL}$ droplets by hydrodynamic focusing of the aqueous phase (dark orange) with an oil phase (gray) containing fluorosurfactant (Anna et al. 2003). The presence of $1 \mathrm{mg} / \mathrm{mL}$ Dextran-Texas Red $70 \mathrm{kDa}$ (orange fluorescence) allowed droplet production to be monitored (population 1 in $F$ ). After thermocycling each $2.5 \mathrm{pL}$ PCR droplet was reinjected into a fusion device $(C)$ and paired with $16 \mathrm{pL}$ droplets generated on-chip and containing an in vitro transcription system and $20 \mu \mathrm{g} / \mathrm{mL}$ Dextran-Texas Red $70 \mathrm{kDa}$ Texas Red (orange). Pairs of droplets were electrocoalesced by passing between a pair of electrodes $(350 \mathrm{~V})$ and fusion efficiency was estimated on-line by measuring orange fluorescence $(G)$. Nonfused $16 \mathrm{pL}$ droplets were characterized by low orange fluorescence (population 2), while those fused with 1 (population 3 ) or 2 (population 4) 2.5 pL PCR droplets had a significantly increased orange fluorescence. After incubation, droplets were reinjected into a chip to allow picoinjection of the fluorogenic substrate and 7-amino-4-methyl-3-coumarinylacetic acid (blue fluorescent) (D). Droplets were spaced with oil and 4 $\mathrm{pL}$ of the substrate/coumarin mixture was injected into each droplet with a $150 \mathrm{~V}$ AC field applied. The efficiency of the process was assessed by monitoring the blue fluorescence of the coumarin $(H)$. Populations 5, 6, and 7 correspond to populations 2, 3, and 4 in $G$, respectively. Finally the emulsion was reinjected into a microfluidic droplet sorter $(E)$. Blue fluorescence was used to detect picoinjected droplets and green fluorescence to measure the products of the reaction catalyzed by the ribozyme variant present in the droplet. Droplets that contained active ribozymes (green in $E$, population 9 in I) were gated and deflected into the sort channel (top exit channel on inset pictures) by applying a $1200 \mathrm{~V}$ AC pulse. All other droplets were allowed to flow into the waste channel (bottom exit channel on inset pictures). Note that the lower blue fluorescence value on $I$ (compared with $H$ ) is due to the use of a lower magnification objective for the sorting step. For each device, the zone where the fluorescence measurement was made is indicated by a blue arrow. Blue lines on micrographs $E$ show the location of the laser lines used to scan the droplets.

catalytic activity was G17A (lane 3). Moreover, the presence of one of the other main mutations (C53U, A57G, and/or C58A) together with G17A led to a further strong increase in activity (lanes 9-12). Interestingly, adding separately either G30A or one of the secondary mutation (A18C or G55U) had no significant effect on activity (lanes 13-15), but their simultaneous presence (lanes 16 and 17) led to the most active improved X-motif variants (iXms 1 and iXms 2), isolated from round 9 , both able to catalyze the reaction in trans under multiple-turnover conditions at a rate $\left(k_{\text {cat }}^{\text {ss }}=0.48 \mathrm{~min}^{-1}\right.$; Fig. 1C) close to that of the original X-motif acting in cis under single-turnover conditions $\left(k_{\mathrm{obs}} \sim 0.7 \mathrm{~min}^{-1}\right.$ ) (Tang and Breaker 2000). Surprisingly, extensions were also found to be impor- tant as their removal led to a significant decrease in activity (lanes 18 and 19). Finally, attempt to introduce additional mutations led to a drop in activity indicating that iXms were probably optimal molecules (lanes 20 and 21).

Further characterization (Table 1) revealed that mutations acquired by iXm1 and iXm2 increased the substrate $K_{\mathrm{d}}$ by $>150$-fold ( $K_{\mathrm{d}}$ increased from 6.5 to $>1000 \mathrm{nM}$ ) compared with the original $\mathrm{X}$-motif. It was not possible to measure the Michaelis constant, $K_{\mathrm{M}}$, of the original or extended Xmotifs directly, however when product release is the rate-limiting step in the reaction, the Michaelis constant, $K_{\mathrm{M}} \approx K_{d}$. The $K_{\mathrm{M}}$ of both improved enzymes was measured directly $\left(K_{\mathrm{M}}=1680\right.$ and $1910 \mathrm{nM}$ for iXm1 and iXm2, respectively) 
TABLE 2. Experimental parameters

\begin{tabular}{|c|c|c|c|c|c|c|}
\hline Round & $\begin{array}{c}\text { PCR droplets } \\
\text { occupancy } \\
(\%)\end{array}$ & $\begin{array}{c}\lambda \\
\text { value }\end{array}$ & $\begin{array}{l}\text { Fusion } \\
\text { efficiency } \\
(\%)\end{array}$ & $\begin{array}{c}\text { Substrate } \\
\text { concentration } \\
(\mu \mathrm{M})\end{array}$ & $\begin{array}{l}\text { Number of } \\
\text { analyzed } \\
\text { droplets }\end{array}$ & $\begin{array}{l}\text { Number } \\
\text { of sorted } \\
\text { droplets }\end{array}$ \\
\hline \multicolumn{7}{|c|}{ Evolution at high mutation rate } \\
\hline 1 & 18 & 0.20 & 80 & 4 & $2,041,668$ & 20,012 \\
\hline 2 & 17 & 0.19 & 80 & 4 & 152,476 & 1522 \\
\hline 3 & 15 & 0.16 & 70 & 6 & $2,046,665$ & 3146 \\
\hline 4 & 10 & 0.11 & 75 & 8 & 339,130 & 782 \\
\hline 5 & 15 & 0.16 & 77 & 10.6 & $1,418,750$ & 4317 \\
\hline 6 & 18 & 0.20 & 80 & 13.2 & 125,053 & 1535 \\
\hline 7 & 15 & 0.16 & 73 & 13.2 & $1,660,007$ & 10,168 \\
\hline 8 & 16 & 0.17 & 85 & 16 & 838,235 & 5711 \\
\hline 9 & 18 & 0.20 & 90 & 20 & 193,333 & 2956 \\
\hline \multicolumn{7}{|c|}{ Evolution at low mutation rate } \\
\hline 1 & 18 & 0.20 & 75 & 4 & $1,111,765$ & 10,675 \\
\hline 2 & 17 & 0.19 & 78 & 4 & 366,666 & 550 \\
\hline 3 & 11 & 0.12 & 65 & 6 & 533,333 & 3271 \\
\hline 4 & 16 & 0.17 & 80 & 8 & 413,335 & 618 \\
\hline 5 & 13 & 0.14 & 76 & 10.6 & 876,903 & 1220 \\
\hline 6 & 16 & 0.17 & 83 & 13.2 & 183,333 & 1178 \\
\hline 7 & 16 & 0.17 & 90 & 16 & 307,692 & 4000 \\
\hline 8 & 17 & 0.19 & 90 & 20 & 162,500 & 2607 \\
\hline
\end{tabular}

The occupancy of PCR droplets, determined by measuring the fraction of PCR droplets having an increased green fluorescence (using EvaGreen) after thermocycling, the corresponding calculated mean number of template DNA molecules per droplet, $\lambda$, and the measured fusion efficiency are given for each round. The total number of droplets analyzed at the end of each round of selection as well as the number of droplets sorted as positive and recovered is also indicated. indicating that the $K_{\mathrm{M}}$ has evolved to approach the substrate concentration $(20 \mu \mathrm{M}$ in the last round of selection), as predicted for the evolution of an efficient enzyme (Fersht 1999). Hence, the $k_{\text {cat }}^{\text {ss }}$ may be underestimated as the ribozymes are no longer saturated with substrate at the working concentration used for the assays $(4 \mu \mathrm{M})$. The mutations acquired by iXm1 and iXm2 also confer a modest 3.4- to 4.0-fold reduction in product inhibition (Table 1). Furthermore, no burst phase was observed in the reaction catalyzed by $\mathrm{iXm} 1$ or iXm2 (Fig. 1C), indicating that product release is no longer rate limiting. These observations, together with the location of most of the selected positive mutations in substrate-binding site of iXms ribozymes, indicate that the elevated $k_{\text {cat }}^{\text {ss }}$ of the iXms results mainly from a reduction of affinity for the reaction products which allows more rapid product release and turnover, but that the changes required to decrease product affinity result in an even more dramatic decrease in the affinity for the substrate, as proposed for other ribozymes (Herschlag and Cech 1990a,b; Young et al. 1991; StageZimmermann and Uhlenbeck 1998; Shih and Been 2000; Hsieh et al. 2009).

\section{DISCUSSION}

In this work, we present a microfluidic-assisted in vitro compartmentalization (IVC) methodology allowing ribozymes to be selected under multiple-turnover conditions while avoiding several of the limitations reported for conventional IVC (Griffiths and Tawfik 2006). The high monodispersity of droplets generated in microfluidic systems has already proved its value for continuous evolution of ribozymes to isolate neomycin-resistant RNA ligases (Paegel and Joyce 2010). This approach used a radial array of aqueous flow nozzles to generate droplets at high throughput $\left(10^{7}-10^{8}\right.$ per hour $)$ but is restricted to ribozymes compatible with continuous evolution procedures (i.e., RNA ligases and derivatives). Our workflow (Fig. 2A) is based on the use of four consecutive droplet-based microfluidic chips allowing the generation fusion, picoinjection, and fluorescenceactivated sorting of highly monodisperse droplets in high-throughput regimes. The main advantage is the capacity to perform serial addition of reagents (by droplet fusion or picoinjection). This allows single genes compartmentalized in droplets to be amplified in situ prior to expression, which is expected to reduce the phenotypic variance observed when expressing single genes in droplets (Fallah-Araghi et al. 2012). In addition, uncoupling the activity assay from gene expression makes it possible to screen for activity in conditions incompatible with gene expression (Mazutis et al. 2009b). Indeed, in this study, we discovered that T7 RNA polymerase interfered with the fluorogenic nuclease assay. However, picoinjecting an assay mixture with a high salt concentration after the genes were expressed to inactivate the T7 RNA polymerase enabled us to use the fluorogenic assay. Moreover, this uncoupling will be essential when screening for extremely fast catalysts with reaction rates much higher than gene expression rate. It is likely that the combination of the different effects discussed above (droplets polydispersity, biological variance, and incompatibility between gene expression and activity assay) would have precluded the isolation of improved X-motif variants by conventional IVC where all the reagents are present in the droplet from the beginning. This methodology is also highly flexible: It should enable the in vitro evolution of RNAs with a wide range of different activities and can also be adapted for in vitro evolution of DNA or proteins.

The exquisite control over reaction conditions offered by our approach, allowed us to efficiently evolve one of the most active self-cleaving ribozymes (the $\mathrm{X}$-motif) to catalyze multiple-turnover reactions. Indeed, under multiple-turnover conditions the rate of the reaction catalyzed by the $\mathrm{X}$ motif ribozyme is limited by product release rather than 

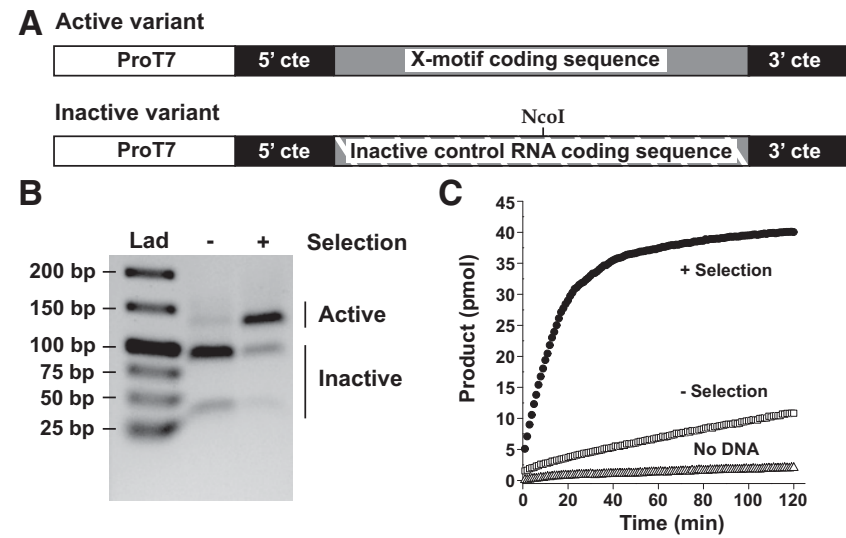

FIGURE 3. Model selection. (A) Gene constructs. Genes coding for the extended X-motif ribozyme and an inactive control RNA are shown. Both genes are of the same length and under the control of a T7 RNA polymerase promoter (ProT7) and code for RNA bearing $5^{\prime}$ and $3^{\prime}$ constant regions (cte). The position of the unique NcoI restriction found only in the inactive control RNA is indicated. (B) Electrophoretic analysis of the model selection. A mixture of one active for 49 inactive genes was subjected to the selection procedure. A PCR was performed on the reaction mixture before selection (-) or on the sorted droplets (+). PCR products were then digested by NcoI prior to being analyzed on $2 \%$ agarose gel. The X-motif gene did not possess an NcoI cleavage site and stayed intact while the gene for the inactive control RNA was cut by the enzyme into two fragments. X-motif genes were enriched 28 -fold. (C) Activity assay. A PCR was performed on the reaction mixture before selection, on the sorted droplets, or with no template added. PCR products were incubated with an in vitro transcription (IVT) mixture for $1 \mathrm{~h}$ at $37^{\circ} \mathrm{C}$. An aliquot of IVT mixture was then mixed with fluorogenic substrate and the fluorescence (Ex. $488 \mathrm{~nm} / \mathrm{Em} .525 \mathrm{~nm}$ ) was monitored at $37^{\circ} \mathrm{C}$. While only background activity was observed in the absence of PCR product (open triangles) and weak activity was obtained when DNA originated from unsorted droplets (open squares), the initial rate increased 26-fold after the sorting procedure (filled circles), compared with the unsorted droplets.

the chemical step. This effect, which has also been reported for a number of other ribozymes (Herschlag and Cech 1990a,b; Young et al. 1991; Stage-Zimmermann and Uhlenbeck 1998; Shih and Been 2000; Hsieh et al. 2009) can be explained by the extensive number of contacts formed between the enzyme and its substrate and products (Fig. 1B). However, applying our selection workflow to the molecule led to evolved X-motif variants, $\mathrm{iXm} 1$ and $\mathrm{iXm} 2$, able to catalyze the in trans cleavage of substrate RNA under multipleturnover conditions with a 28 -fold improved $k_{\text {cat }}^{\text {ss }}$ of 0.48 $\mathrm{min}^{-1}$, almost as fast as the original ribozyme could catalyze the in cis reaction under single-turnover conditions $\left(k_{\mathrm{obs}} \sim\right.$ $\left.0.7 \mathrm{~min}^{-1}\right)$. This improved $k_{\mathrm{cat}}^{\text {ss }}$ together with the absence of a burst phase (Fig. 1C) indicates that product release was no longer rate limiting. In agreement with this, most of the mutations were found in the substrate-binding site of the enzyme. The only exception was the mutation G30A, found in a loop reported as dispensable for X-motif activity. This mutation is therefore likely to have an indirect effect, but further investigations are required to shed light on its exact contribution.
It has previously been proposed that the X-motif should theoretically be able to evolve to catalyze RNA cleavage under single-turnover conditions with a $k_{\text {cat }}$ of $80,000 \mathrm{~min}^{-1}$ (Emilsson et al. 2003). However, under multiple-turnover conditions the rate of the reaction catalyzed by the X-motif ribozyme is limited by product release rather than the chemical step. Here, for the most active evolved X-motif variants, iXm1 and iXm2, product release was no longer rate limiting but the $k_{\text {cat }}^{\text {ss }}$ was still only $0.48 \mathrm{~min}^{-1}$. It is likely that the iXms variants obtained in the current study are the optimal forms of X-motif obtainable using point mutagenesis as the only source of genetic diversity. To further evolve, the molecule might require an increase in the sequence space via deletions and insertions (e.g., through recombination events with fragments of RNA from other sources). Indeed, one can observe the effect of insertions directly in this study: The $k_{\text {cat }}^{\text {ss }}$ of the original X-motif was increased 4.0-fold when constant regions were appended at both ends of the molecule to allow gene amplification and optimal and homogeneous transcription initiation (Fig. 1C), and when these extensions were removed from the iXms variants at the end of the evolution process, $k_{\text {cat }}^{\text {ss }}$ was reduced 1.85-3.20-fold (Fig. 5, compare lanes 16 and 17 with 18 and 19). While a complete understanding of their exact role would require further investigation, one can infer that iXms integrated and made use of these extensions to improve product release. Additional insertion events, occurring in the catalytic core could confer additional functions on the enzyme, such as the recognition of cofactors that could increase its chemical repertoire. Future experiments will aim to use the workflow described here, combined with techniques to generate genetic diversity by point mutation, deletion and insertion, to isolate very fast ribozymes and ribozymes evolved to use cofactors such as amino acids (which could shed light on the origin of translation and evolutionary transition out of the RNA World).

\section{MATERIALS AND METHODS}

\section{Oligonucleotides}

PCR amplification was performed with primers Xmot-Fwd (5'-GT AAAACGACGGCCAGTGCCAAGCTTGCATGCTAATACGACTC ACTATAGGAAGACGTAGCAAG-3') and Xmot-Rev (5'-TGTGTT CTCTGTCATCTCTCTG-3'), both synthesized by Sigma-Aldrich.

In addition, unlabeled RNA substrate S21 (5'-AGUCCUGAUGG UUACUCCAAU-3') reaction product P5 (5'-GUCCUGAUG-3') and P3 (5'-GUUACUCCAAU- $\left.3^{\prime}\right)$ were also synthesized by Sigma-Aldrich, while the dually labeled fluorogenic RNA Atto 488-S21-BHQ1 (5'-Atto488-AGUCCUGAUGGUUACUCCAAUBHQ1-3') was obtained from Eurogentec.

\section{Microfluidic device fabrication and operation}

Microfluidic devices were obtained using a classic replica molding process as described previously (Mazutis et al. 2009a). Briefly, molds 

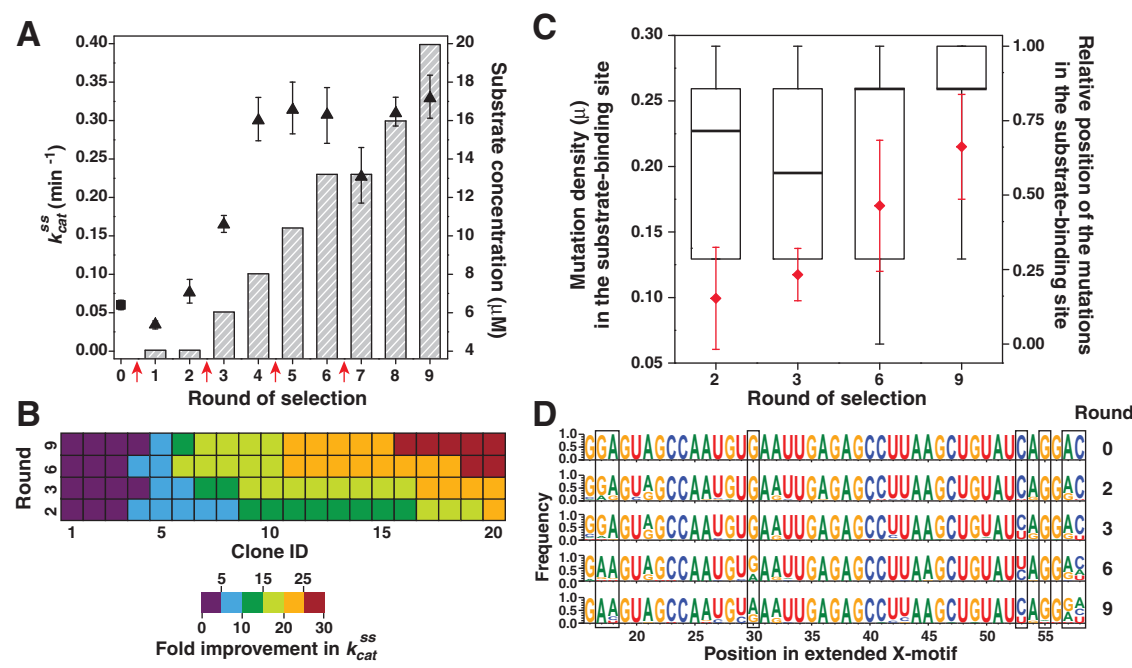

FIGURE 4. In vitro evolution of the extended X-motif. (A) Multiple-turnover activity of the selected libraries at high mutation rate (1.6 mutations per gene) in different rounds of selection. The $k_{\text {cat }}^{\text {ss }}$ was determined for the parental extended X-motif (square) and the selected library (triangle). Steps at which new genetic diversity was introduced by random mutagenesis are indicated by red arrows. The total concentration of substrate RNA (fluorogenic and nonfluorogenic) used in the selection is represented by the dashed bars. The concentration of fluorogenic substrate was constant in all rounds $(4 \mu \mathrm{M})$. The values are the mean of at least three independent measurements and error bars correspond to \pm 1 standard deviation. $(B)$ Activity of cloned variants. The $k_{\text {cat }}^{\text {ss }}$ of 20 variants from rounds $2,3,6$, and 9 was tested and normalized using the $k_{\text {cat }}^{\text {ss }}$ of the nonextended $\mathrm{X}$-motif. The clones were ordered and numbered (ID) according to their $k_{\text {cat }}^{\text {ss }}$. (C) Density and position of mutations in the substrate-binding site throughout the evolution process. The red diamonds represent the mutation density, $\mu$, which is the average number of mutations in the substrate-binding site (SBS) divided by the length of the SBS, calculated for the rounds of selection 2 3,6 , and 9. Error bars shown in red correspond to \pm 1 standard deviation. In addition, for each tested round of selection, the relative position (RP) of the mutations was calculated using RP $=(n-1) /(l-1)$, where $n$ is the position of the residue in the SBS starting the count from the residue the closest to the active site and $l$ is the length of the SBS. The relative position can vary between 0 (mutation at the positions the closest to the active site) and 1 (mutation at the positions the furthest to the active site, therefore at the extremity). Results are shown as a box and whisker plot where the bold line represents the median; the lower and upper limits of the box, respectively, correspond to the first and third quartile; and the whiskers spread from the maximum to the minimum RP values. (D) Sequence evolution. For rounds 2, 3, 6, and 9, the 20 clones characterized in $B$ were sequenced and, after sequence alignment, a logo representation generated using WebLogo3.3 (http://weblogo.threeplusone.com).

were first prepared by standard photolithography methods. SU-8 2010, SU-8 2015, SU-8 2020, or SU-8 2025 photoresist (MicroChem Corp.) were used to pattern, respectively, 10-, 15-, 20-, or 25- $\mu \mathrm{m}$ deep channels onto silicon wafers (Siltronix). Microfluidic devices were then fabricated in polydimethylsiloxane (PDMS) using conventional soft lithography methods (Xia and Whitesides 1998). The channels of the devices were passivated with a solution of $1 \%$ (v/v) $1 \mathrm{H}, 1 \mathrm{H}, 2 \mathrm{H}, 2 \mathrm{H}$ perfluorodecyltrichlorosilane $(97 \%, \mathrm{ABCR}$ $\mathrm{GmbH}$ and Co.) in HFE7100 (3M) and subsequently flushed with compressed air. Patterned electrodes were filled with metal by heating the microfluidic chip to $90^{\circ} \mathrm{C}$ and injecting molten $51 \mathrm{In} / 32.5 \mathrm{Bi} /$ 16.5Sn low temperature solder (Indium Corporation) (Siegel et al. 2007). Finally, electrical connections with the solder were made with short pieces of electric wires (Radiospares). Key dimensions and depth of microfluidic devices are given on Supplemental Figures S3-S6.

Aqueous phases were loaded in I.D. $0.75 \mathrm{~mm}$ PTFE tubings (Thermo Scientific) and oils were loaded in $2 \mathrm{~mL}$ Micrew Tubes
(Thermo Scientific). Liquids were injected into microfluidic devices at constant and highly controlled flow-rates using a 7-bar MFCS pressure-driven flow controller (Fluigent) equipped with Flowells $(7 \mu \mathrm{L} / \mathrm{min}$ flow meters) allowing for operation in flow-rate controlled mode.

\section{Optical set-up, data acquisition, and control system}

The optical setup was based on an inverted microscope (Nikon Eclipse Ti-S) mounted on a vibration-dampening platform (Thorlabs B75150AE). The beams of a $375 \mathrm{~nm}$ laser (CrystaLaser DL375-020-O) and a $488 \mathrm{~nm}$ laser (CrystaLaser DL488-050-O) were combined using a dichroic mirror (Semrock Di02-R405-25×36), shaped as lines using a pair of lenses (Semrock LJ1878L2-A and LJ1567L1-A) and directed into the microscope objective (Nikon Super Plan Fluor 20× ELWD or Nikon Super Plan Fluor 40× ELWD) to be focused in the middle of the channel at the detection point. The emitted fluorescence was collected by the same objective and separated from the laser beams by a multiedges dichroic mirror (Semrock Di01-R405/488/561/635-25×36). Blue (coumarin) fluorescence was resolved from green (Atto488/EvaGreen) and orange (Texas Red) fluorescence by a third dichroic mirror (Semrock LM01-480-25). Then green fluorescence was separated from orange fluorescence by an additional dichroic mirror (Semrock FF562-Di03-25×36). Fluorescence was finally measured by three photomultiplier tubes (Hamamatsu H10722-20) equipped with bandpass filters (Semrock FF01-445/45-25, FF01-600/37-25, and FF03-525/50-25 for blue, green, and orange detection, respectively). Signal acquisition from the PMTs and control of fluorescence-activated dielectrophoretic sorting (Baret et al. 2009) was performed using an intelligent data acquisition (DAQ) module featuring a user-programmable FPGA chip (National Instruments PCI-7851R) driven by internally developed firmware and software. To monitor the experiment we used an additional dichroic mirror (Semrock FF665-Di02-25×36) to split light to a CCD camera (Allied Vision Technologies Guppy F-033). A long-pass filter (Semrock BLP01-664R-25) prevented potentially damaging reflections of the lasers into the camera.

\section{Gene library generation}

Gene libraries were prepared with JBS dNTP-Mutagenesis Kit (Jena Bioscience) following the manufacturer's instructions. Briefly, $10 \mathrm{fmol}$ of template DNA diluted in a $200 \mu \mathrm{g} / \mathrm{mL}$ yeast total RNA solution (Ambion) were placed in a reaction mixture containing $0.2 \mu \mathrm{M}$ of each primer (Xmot-Fwd and Xmot-Rev), $0.5 \mathrm{mM}$ of 


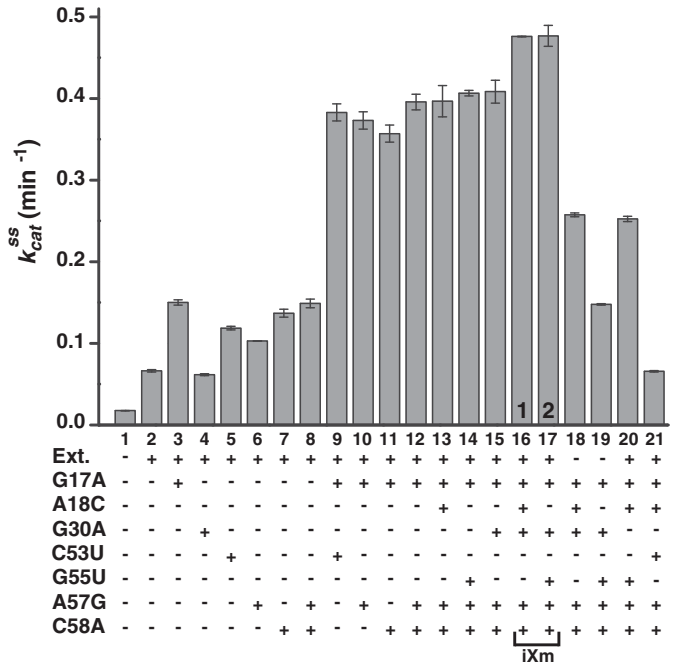

FIGURE 5. Contribution of selected mutations. The $k_{\text {cat }}^{\text {ss }}$ was calculated for each purified RNA. The values are the mean of at least three independent measurements and error bars correspond to \pm 1 standard deviation. Improved X-motifs (iXm) are indicated and the corresponding bars are numbered (1 or 2$)$.

each dNTP, 0.5 mM 8-oxo-2' -deoxyguanosine triphosphate (8-oxodGTP), $0.5 \mathrm{mM}$ 6-(2-deoxy- $\beta$-D-ribofuranosyl)-3,4-dihydro- $8 \mathrm{H}$ pyrimido-[4,5-c][1,2] oxazin-7-one triphosphate (dPTP) (Zaccolo et al. 1996), 0.1 units/ $\mu \mathrm{L}$ of Taq polymerase and the reaction buffer at the recommended working concentration. The mixture was then thermocycled starting with an initial step of denaturation of $2 \mathrm{~min}$ at $92^{\circ} \mathrm{C}$ followed by 2 (low mutation rate) or 4 (high mutation rate) cycles of: $1 \mathrm{~min}$ at $92^{\circ} \mathrm{C}, 1 \mathrm{~min}$ at $55^{\circ} \mathrm{C}$, and $5 \mathrm{~min}$ at $72^{\circ} \mathrm{C}$. To generate analog-free template, $1 \mu \mathrm{L}$ of the mixture was then transferred in $30 \mu \mathrm{L}$ of analog-free PCR mixture containing $0.2 \mathrm{mM}$ of each dNTP, $0.2 \mu \mathrm{M}$ of each primer (Xmot-Fwd and Xmot-Rev), 0.1 units/ $\mu \mathrm{L}$ of DreamTaq (Fermentas) and the corresponding buffer at the recommended working concentration. The mixture was then thermocycled starting with an initial denaturation step of 2 min at $92^{\circ} \mathrm{C}$ followed by 2 cycles of: $1 \mathrm{~min}$ at $92^{\circ} \mathrm{C}, 1 \mathrm{~min}$ at $55^{\circ} \mathrm{C}$, and $5 \mathrm{~min}$ at $72^{\circ} \mathrm{C}$, followed by 20 cycles of: $30 \mathrm{sec}$ at $92^{\circ} \mathrm{C}, 30 \mathrm{sec}$ at $55^{\circ} \mathrm{C}$, and $45 \mathrm{sec}$ at $72^{\circ} \mathrm{C}$. PCR products were purified with a "Wizard SV Gel and PCR Clean-Up System" kit (Promega) and quantified with a Nanodrop (Thermo Scientific). Mutation rates were determined by cloning and sequencing a sub fraction of libraries generated using the extended X-motif as template.

\section{Emulsion PCR}

Gene libraries were diluted in a $200 \mu \mathrm{g} / \mathrm{mL}$ yeast total RNA solution (Ambion) down to a concentration of four DNA molecules per picoliter. The solution was then diluted 50 times in a PCR mixture consisting of $0.2 \mathrm{mM}$ of each dNTP, $0.2 \mu \mathrm{M}$ of each primer (Xmot-Fwd and Xmot-Rev), $1 \mathrm{mg} / \mathrm{mL}$ Dextran-Texas Red $70 \mathrm{kDa}$ (Molecular Probes), $1 \times$ EvaGreen (Biotium), 0.1 units $/ \mu \mathrm{L}$ of DreamTaq (Fermentas) and the corresponding buffer at the recommended working concentration. The solution was loaded into a length of PTFE tubing, connected between the flow meter (Fluigent) and the microfluidic chip (Supplemental Fig. S3). The aqueous phase was dispersed into $2.5 \mathrm{pL}(\sim 12 \mathrm{kHz})$ droplets, containing an average $(\lambda)$ of 0.2 DNA molecules per droplet, by flow focusing (Anna et al. 2003) with HFE 7500 fluorinated oil (3 M) supplemented with $3.5 \%(\mathrm{w} / \mathrm{w})$ of a fluorinated surfactant. The diblock copolymer surfactant was synthesized as described in Chen et al. (2011) by conjugating Krytox FSH (DuPont), a perfluoropolyether monocarboxylate (MW $\sim 5000 \mathrm{~g} / \mathrm{mol}$ ), with Jeffamine M-1000 (Huntsman), a polyether monoamine (MW $\sim 1000 \mathrm{~g} /$ $\mathrm{mol}$ ). Droplets were detected by their orange fluorescence (Texas Red), their production frequency measured and used to determine droplet volumes by calculating the ratio of aqueous flow rate/droplet production frequency. In addition, assuming that droplets flow at a constant velocity at the detection point, it is possible to correlate the time a droplet needs to pass the laser to its width and to measure emulsion dispersity by calculating the coefficient of variation (CV) of the population from the standard deviation, $\sigma$, and the mean drop width, $w$ : $\mathrm{CV}=(\sigma / w) \times 100$.

Flow rates were adjusted to produce $2.5 \mathrm{pL}$ droplets, the emulsion was collected in a $0.2 \mathrm{~mL}$ PCR tube closed by a PDMS plug as described (Pekin et al. 2011) and thermocycled starting with an initial denaturation step of $2 \mathrm{~min}$ at $98^{\circ} \mathrm{C}$ followed by 30 cycles of: $10 \mathrm{sec}$ at $98^{\circ} \mathrm{C}, 30 \mathrm{sec}$ at $55^{\circ} \mathrm{C}$, and $30 \mathrm{sec}$ at $72^{\circ} \mathrm{C}$.

\section{Droplet fusion and in vitro transcription}

PCR droplets were reinjected into a droplet fusion device (Supplemental Fig. S4) and spaced with HFE 7500 fluorinated oil supplemented with $2 \%(\mathrm{w} / \mathrm{w})$ of fluorinated surfactant. In parallel, $16 \mathrm{pL}(\sim 2 \mathrm{kHz})$ droplets were produced on-chip using the same oil stream and an aqueous phase of in vitro transcription (IVT) mixture containing: $2 \mathrm{mM}$ of each NTP, $25 \mathrm{mM} \mathrm{MgCl}_{2}, 40 \mathrm{mM}$ Tris- $\mathrm{HCl}$, pH 8.0, $50 \mathrm{mM} \mathrm{NaCl}, 5 \mathrm{mM}$ DTT, $1 \mathrm{mM}$ spermidine, $20 \mu \mathrm{g} / \mathrm{mL}$ Dextran-Texas Red $70 \mathrm{kDa}$ (Molecular Probes), and 0.4 units/ $\mu \mathrm{L}$ T7 RNA polymerase (New England Biolabs). The IVT mixture was loaded in a length of PTFE tubing kept on ice and both droplet production (volume calculated as above) and fusion events were monitored using orange fluorescence, and flow rates were adjusted to generate $16 \mathrm{pL}$ IVT droplets and maximize 1 to 1 PCR/IVT droplet pairing while limiting 2 to 1 PCR/IVT droplet pairing. Pairs of droplets were electrocoalesced (Chabert et al. 2005; Mazutis et al. 2009a) by passing between a pair of built-in electrodes to which an electric field of $350 \mathrm{~V} \mathrm{AC}(30 \mathrm{kHz})$ was applied using a high voltage amplifier (Model 623b, Trek). The emulsion was collected in a $0.5 \mathrm{~mL}$ PCR tube closed by a PDMS plug and incubated at $37^{\circ} \mathrm{C}$ for $30 \mathrm{~min}$ to allow gene transcription to occur.

\section{Substrate picoinjection and activity assay}

Fused PCR/IVT droplets were reinjected into a picoinjection device (Supplemental Fig. S5; Abate et al. 2010) and spaced with HFE 7500 fluorinated oil supplemented with $2 \%(\mathrm{w} / \mathrm{w})$ fluorinated surfactant. Gene transcription was stopped and ribozymes activity assayed using a reaction mixture containing $1 \mathrm{M} \mathrm{NaCl}$ (to inactivate $\mathrm{T} 7$ RNA polymerase), $66 \mathrm{mM} \mathrm{MgCl}_{2}, 10 \mu \mathrm{M}$ of 7-amino-4-methyl3-coumarinylacetic acid (Sigma-Aldrich), $20 \mu \mathrm{M}$ of Atto488-S21BHQ1 fluorogenic RNA substrate (Eurogentec) and the desired concentration $(0,10,20,33,46,60$, or $80 \mu \mathrm{M})$ of nonlabeled S21 substrate (Sigma-Aldrich). Flow rates were adjusted to reach a droplet reinjection frequency of $2 \mathrm{kHz}$ and the reaction mixture was 
injected at a flow rate of $25 \mu \mathrm{L} / \mathrm{h}$ allowing injection of $4 \mathrm{pL}$ of reaction mixture into each passing droplet. The picoinjection was triggered by applying an electric field of $150 \mathrm{~V} \mathrm{AC}(30 \mathrm{kHz})$ to builtin electrodes using a high voltage amplifier (Model 623b, Trek). The blue fluorescence of the coumarin dye was used to monitor the process and assess its quality by making sure that the real-time calculated CV was $<15 \%$. The emulsion was collected in a $0.5 \mathrm{~mL}$ PCR tube closed by a PDMS plug and incubated at $37^{\circ} \mathrm{C}$ for 30 min to allow substrate transformation by active ribozymes to occur.

\section{Droplet sorting}

Picoinjected droplets were reinjected into a droplet-sorting device (Supplemental Fig. S6) and spaced with surfactant-free HFE-7500 fluorinated oil. Flow rates were adjusted so that droplets were reinjected at a frequency of $\sim 300 \mathrm{~Hz}$. Droplets were detected by their orange fluorescence and sorted based on their blue (concentration of picoinjected substrate) and green (concentration of product) fluorescence. The $1 \%$ most green fluorescent droplets having received the correct amount of substrate were gated (Fig. 2I) and deflected into the recovery channel by applying a $1200 \mathrm{~V} \mathrm{AC}(30 \mathrm{kHz})$ electric field using a high voltage amplifier (Ahn et al. 2006; Baret et al. 2009). Sorted droplets were collected in an Eppendorf tube via a length of PTFE tubing. At the end of the process, the recovered oil/droplet mixture was successively supplemented with $200 \mu \mathrm{L}$ of HFE 7500 fluorinated oil, $100 \mu \mathrm{L}$ of $1 \mathrm{H}, 1 \mathrm{H}, 2 \mathrm{H}, 2 \mathrm{H}$-perfluoro-1octanol (Sigma-Aldrich) and $200 \mu \mathrm{L}$ of $200 \mu \mathrm{g} / \mathrm{mL}$ yeast total RNA solution (Ambion) by flushing the reagent through the PTFE tubing. The mixture was finally mixed by vortexing and briefly centrifuged. The upper aqueous phase was then recovered and transferred into a new tube.

\section{Enrichment measurement}

Sorts were validated by measuring enrichment for activity. DNA contained in an aliquot of aqueous phase obtained after sorting and emulsion breaking was reamplified by PCR using a mixture containing $0.2 \mathrm{mM}$ of each dNTP, $0.2 \mu \mathrm{M}$ of each primer (Xmot-Fwd and Xmot-Rev), 0.1 units/ $\mu \mathrm{L}$ of DreamTaq (Fermentas) and the corresponding buffer at the recommended working concentration.

For the model selection, the experiment was first validated by restriction analysis. The PCR mixture was purified with a "Wizard SV Gel and PCR Clean-Up System" kit (Promega) and the DNA contained in $20 \mu \mathrm{L}$ of elution incubated with 10 units of NcoI (Fermentas) and the corresponding buffer at the recommended working concentration. After overnight incubation at $37^{\circ} \mathrm{C}$, the mixture was loaded on a $2 \%$ agarose gel and DNA stained with ethidium bromide. The stained gel was imaged on a GelDoc EZ Imager (Bio$\mathrm{Rad})$ and bands quantified using Image Lab (Bio-Rad).

More generally, for each selection, PCR products were used as templates for in vitro transcriptions (IVT) by incubating $5 \mu \mathrm{L}$ of the raw PCR product in a $45 \mu \mathrm{L}$ mixture containing $2 \mathrm{mM}$ of each NTP, $25 \mathrm{mM} \mathrm{MgCl}_{2}, 40 \mathrm{mM}$ Tris- $\mathrm{HCl}, \mathrm{pH} 8.0,50 \mathrm{mM}$ $\mathrm{NaCl}, 5 \mathrm{mM}$ DTT, $1 \mathrm{mM}$ spermidine, and 0.4 units/ $\mu \mathrm{L}$ T7 RNA polymerase (New England Biolabs). After $1 \mathrm{~h}$ at $37^{\circ} \mathrm{C}, 2 \mu \mathrm{L}$ of the RNAcontaining IVT mixture were mixed with $8 \mu \mathrm{L}$ of reaction mixture containing $40 \mathrm{mM}$ Tris- $\mathrm{HCl}, \mathrm{pH} 8.0,25 \mathrm{mM} \mathrm{MgCl} 2,250 \mathrm{mM}$ $\mathrm{NaCl}$, and $4 \mu \mathrm{M}$ of Atto488-S21-BHQ1 fluorogenic RNA substrate. After mixing, the mixture was placed in a real-time Thermocycler
(Mx3005P, Agilent) kept at $37^{\circ} \mathrm{C}$ and the fluorescence measured every minute on FAM channel of the device (ex: $492 \mathrm{~nm} / \mathrm{em}: 516 \mathrm{~nm}$ ). Enrichment was then calculated from the ratio of initial reaction rates before and after selection.

\section{Cloning, sequence analysis and activity screening}

At the end of evolution process, individual variants were cloned into plasmids using InsTAclone PCR cloning kit (Thermo Scientific) and resulting constructs were introduced into Electro-10 blue strains (Agilent) using $2 \mathrm{~mm}$ electroporation cuvettes and a MicroPulser (Bio-Rad). Bacteria were plated on LB-Ampicillin agar plates and colonies were allowed to develop during an overnight incubation at $37^{\circ} \mathrm{C}$. Twenty isolated colonies of each transformation were then grown in liquid LB-Ampicillin until saturation, plasmid DNA was extracted from bacteria using GeneJet Plasmid Miniprep kit (Thermo Scientific) and sequences were determined by Sanger sequencing (GATC Biotech.). Sequence alignments were generated using ClustalX (Larkin et al. 2007). In parallel, the gene of each variant was PCR-amplified, in vitro transcribed and its activity assayed as for Enrichment measurements (see above).

\section{Ribozyme purification}

The most active variants identified during the screening were in vitro transcribed as before but in a larger reaction volume $(500 \mu \mathrm{L})$ and for $3 \mathrm{~h}$ at $37^{\circ} \mathrm{C}$. DNA was then removed by adding 10 units of Baseline Zero DNase (Epicentre) and the corresponding buffer at the recommended working concentration. After an extra hour at $37^{\circ} \mathrm{C}$, proteins were eliminated by phenol extraction and RNA recovered by ethanol precipitation and centrifuged for $20 \mathrm{~min}$ at $20,000 g$. Dry pellets were suspended in $20 \%$ glycerol, $0.02 \%$ xylene cyanol, $0.02 \%$ bromophenol blue, $1 \times \mathrm{TBE}$ and $8 \mathrm{M}$ urea, and the solution loaded on a $12 \%$ acrylamide/bisacrylamide (19/1), $8 \mathrm{M}$ urea denaturing gels. The position of the RNA was determined by UV-shadowing and the corresponding piece of gel excised and transferred into a dialysis tube (MWCO $=3500$, Spectrum Labs) with TE buffer (Sigma-Aldrich). Dialysis tubes were closed, placed in a horizontal electrophoresis system (Bio-Rad) and subjected to a 100V DC field for $1 \mathrm{~h}$. Residual gel fragments were removed from aqueous phases using $0.45 \mu \mathrm{M}$ microfuge filters (VWR). RNA was then recovered by ethanol precipitation, dry pellets dissolved in DEPC-treated water and quantified with a Nanodrop Spectrophotometer (Thermo Scientific).

\section{Enzymatic characterization}

Four picomoles of purified ribozymes were placed in $10 \mu \mathrm{L}$ of a reaction mixture containing 40 pmol of Atto488-S21-BHQ1 fluorogenic RNA substrate, 40 mM Tris-HCl, pH 8.0, $25 \mathrm{mM} \mathrm{MgCl}_{2}, 250$ $\mathrm{mM} \mathrm{NaCl}$. The mixture was placed in a real-time Thermocycler (Mx3005P, Agilent) kept at $37^{\circ} \mathrm{C}$ and the fluorescence measured every minute on FAM channel of the device (ex: $492 \mathrm{~nm} / \mathrm{em}: 516 \mathrm{~nm}$ ). Fluorescence values were converted into molecules of product generated per ribozyme $(P)$ and catalytic constants determined. Burst phase kinetics were fitted to the burst equation, $P=A t+B$ $\left(1-\mathrm{e}^{-C t}\right)$, described in Wanninayake and Walker (2012), where $A$ is the catalytic constant in the steady state $\left(k_{\text {cat }}^{\text {ss }}\right), B$ is the 
burst amplitude corresponding to the active fraction of ribozyme, $C$ is the catalytic constant during the burst phase $\left(k_{\text {burst }}\right)$ and $t$ is the time. The $k_{\text {cat }}^{s s}$ for the evolved ribozymes iXm1 and iXm2 (where no burst was observed) were calculated from a linear fit to the initial rate. $\mathrm{IC}_{50}$ values were determined using the same procedure but with a reaction mixture supplemented with $0,0.5,5$, $12.5,25,37.5,50$, or $500 \mathrm{pmol}$ of each reaction product P5 and P3 (Sigma-Aldrich).

To measure $K_{\mathrm{M}}, 0.8 \mathrm{pmol}$ of purified ribozymes (iXm1 or iXm2) were placed in $40 \mu \mathrm{L}$ of a reaction mixture containing $40 \mathrm{mM}$ Tris$\mathrm{HCl}, \mathrm{pH}$ 8.0, $25 \mathrm{mM} \mathrm{MgCl}_{2}, 250 \mathrm{mM} \mathrm{NaCl}$, and 8, 20, 40, 80, 160, 240, 320, or 400 pmol of Atto488-S21-BHQ1 fluorogenic RNA substrate. The mixture was placed in a real-time Thermocycler (Mx3005P, Agilent) kept at $37^{\circ} \mathrm{C}$ and the fluorescence measured every minute on the FAM channel of the device (ex: 492 nm/em: 516 $\mathrm{nm})$. Initial rates were measured at the different substrate concentrations and $K_{\mathrm{M}}$ values calculated by fitting to the MichaelisMenten equation:

$$
v_{0}=\frac{V_{\max } S}{K_{\mathrm{M}}+S},
$$

where $v_{0}$ is the initial reaction rate, $V_{\max }$ the maximum reaction rate, $K_{\mathrm{M}}$ the Michaelis constant, and $S$ the concentration of substrate.

While the sensitivity of the fluorogenic assay $(\geq 100 \mathrm{nM})$ allowed direct $K_{\mathrm{M}}$ measurement for the improved X-motifs, the $K_{\mathrm{M}}$ of the original X-motif and its extended form were too low to allow direct measurement of $K_{\mathrm{M}}$ : The substrate concentrations required (starting from 1 to $10 \mathrm{nM}$ ) were far below the sensitivity limit of the assay. However, as it appears that product release is the rate-limiting step in the reaction, the Michaelis constant $K_{\mathrm{M}} \approx K_{d}$ We therefore used a gel shift assay to determine the dissociation constant $\left(K_{\mathrm{d}}\right)$ of the different ribozymes and the substrate.

Unmodified S21 substrate was 5'-labeled by incubating $10 \mathrm{pmol}$ of S21 RNA with $100 \mu \mathrm{Ci}$ of ATP $\left[\gamma-{ }^{32} \mathrm{P}\right](3000 \mathrm{Ci} / \mathrm{mmol}), 10$ units of T4 PolyNucleotide Kinase (Thermo Scientific) and the corresponding buffer at the recommended concentration. After $30 \mathrm{~min}$ at $37^{\circ} \mathrm{C}$, the labeled RNA was purified on a $20 \%$ acrylamide/bisacrylamide (19/1) denaturating polyacrylamide gel, eluted by overnight diffusion in $0.5 \mathrm{mM}$ ammonium acetate, $\mathrm{pH} 7.4,10 \mathrm{mM} \mathrm{MgCl}_{2}$, and $0.1 \%$ SDS, precipitated and washed. The Electrophoretic Mobility Shift Assay was performed in a volume of $10 \mu \mathrm{L}$ with a fixed concentration $(0.15 \mathrm{nM})$ of $5^{\prime}$-labeled S21 RNA and an increasing amount of X-motif, extended X-motif RNA or iXms (0-10 nM, 0-250 nM, and $0-1000 \mathrm{nM}$, respectively) in $65 \mathrm{mM}$ Tris- $\mathrm{HCl}, \mathrm{pH} 8.0$, and 260 $\mathrm{mM} \mathrm{NaCl}$. The mixture was incubated $5 \mathrm{~min}$ at $37^{\circ} \mathrm{C}$ and $5 \mu \mathrm{L}$ of solution containing $0.25 \%$ bromophenol blue, $0.25 \%$ xylene cyanol, and $30 \%$ glycerol was added. S21/X-motif complexes were revealed by loading the mixture on a $12 \%$ acrylamide/bisacrylamide (29:1) nondenaturating gel. We used an incubation time corresponding to the end of the burst phase and assumed that equilibrium was achieved. Substrate transformation was prevented by omitting $\mathrm{Mg}^{2+}$ in the reaction mixture. The good agreement between the $K_{\mathrm{d}}$ values obtained for X-motif in this work $(\sim 6 \mathrm{nM})$ and in a previous estimation based on enzyme kinetics ( $\sim 3 \mathrm{nM}$ ) (Lazarev et al. 2003 ), indicated that $\mathrm{Mg}^{2+}$ was not involved in substrate recognition and that its omission had no effect on enzyme/substrate interaction. Gels were imaged with a Typhoon FLA 7000 and band intensities were quantified using ImageQuant TL v8.1 software. The fraction of unbound substrate was calculated for each concentration of cat- alyst tested and the concentration of ribozyme shifting half of the substrate was assigned as the $K_{\mathrm{d}}$ value.

\section{SUPPLEMENTAL MATERIAL}

Supplemental material is available for this article.

\section{ACKNOWLEDGMENTS}

This work has been published under the framework of the LABEX: ANR-10-LABX-0036_NETRNA and benefits from funding from the French Agence Nationale de la Recherche (ANR) as part of the Investissements d'Avenir program (LABEX: ANR-10-LABX0036_NETRNA). It was also supported by the European Union Seventh Framework Programme [FP7/2007-2013] under grant agreement no. [225167] (eFlux) and [294332] (EvoEvo), the ANR (ANR-08-PCVI-0016-10), the Université de Strasbourg and the Centre National de la Recherche Scientifique (CNRS).

Received September 8, 2014; accepted December 9, 2014.

\section{REFERENCES}

Abate AR, Hung T, Mary P, Agresti JJ, Weitz DA. 2010. High-throughput injection with microfluidics using picoinjectors. Proc Natl Acad Sci 107: 19163-19166.

Agresti JJ, Kelly BT, Jaschke A, Griffiths AD. 2005. Selection of ribozymes that catalyse multiple-turnover Diels-Alder cycloadditions by using in vitro compartmentalization. Proc Natl Acad Sci 102: 16170-16175.

Ahn K, Kerbage C, Hunt TP, Westervelt RM, Link DR, Weitz DA. 2006. Dielectrophoretic manipulation of drops for high-speed microfluidic sorting devices. Appl Phys Lett 88: 024104.

Anna SL, Bontoux N, Stone HA. 2003. Formation of dispersions using "flow focusing" in microchannels. Appl Phys Lett 82: 364-366.

Baret JC, Miller OJ, Taly V, Ryckelynck M, El-Harrak A, Frenz L, Rick C, Samuels ML, Hutchison JB, Agresti JJ, et al. 2009. Fluorescence-activated droplet sorting (FADS): efficient microfluidic cell sorting based on enzymatic activity. Lab Chip 9: 1850-1858.

Bartel DP, Szostak JW. 1993. Isolation of new ribozymes from a large pool of random sequences. Science 261: 1411-1418.

Bartel DP, Unrau PJ. 1999. Constructing an RNA world. Trends Cell Biol 9: M9-M13.

Chabert M, Dorfman KD, Viovy JL. 2005. Droplet fusion by alternating current (AC) field electrocoalescence in microchannels. Electrophoresis 26: 3706-3715.

Chen CH, Sarkar A, Song YA, Miller MA, Kim SJ, Griffith LG, Lauffenburger DA, Han J. 2011. Enhancing protease activity assay in droplet-based microfluidics using a biomolecule concentrator. $J$ Am Chem Soc 133: 10368-10371.

Ellington AD, Szostak JW. 1990. In vitro selection of RNA molecules that bind specific ligands. Nature 346: 818-822.

Ellington AD, Chen X, Robertson M, Syrett A. 2009. Evolutionary origins and directed evolution of RNA. Int J Biochem Cell Biol 41: 254-265.

Emilsson GM, Nakamura S, Roth A, Breaker RR. 2003. Ribozyme speed limits. RNA 9: 907-918.

Fallah-Araghi A, Baret JC, Ryckelynck M, Griffiths AD. 2012. A completely in vitro ultrahigh-throughput droplet-based microfluidic screening system for protein engineering and directed evolution. Lab Chip 12: 882-891.

Fersht A. 1999. Structure and mechanism in protein science: a guide to enzyme catalysis and protein folding. W.H. Freeman, New York. 
Fidalgo LM, Whyte G, Bratton D, Kaminski CF, Abell C, Huck WT. 2008. From microdroplets to microfluidics: selective emulsion separation in microfluidic devices. Angew Chem Int Ed Engl 47: 2042-2045.

Griffiths AD, Tawfik DS. 2000. Man-made enzymes—from design to in vitro compartmentalisation. Curr Opin Biotechnol 11: 338-353.

Griffiths AD, Tawfik DS. 2006. Miniaturising the laboratory in emulsion droplets. Trends Biotechnol 24: 395-402.

Guo MT, Rotem A, Heyman JA, Weitz DA. 2012. Droplet microfluidics for high-throughput biological assays. Lab Chip 12: 2146-2155.

Hartley BS, Kilby BA. 1954. The reaction of p-nitrophenyl esters with chymotrypsin and insulin. Biochem J 56: 288-297.

Herschlag D, Cech TR. 1990a. Catalysis of RNA cleavage by the Tetrahymena thermophila ribozyme. 1. Kinetic description of the reaction of an RNA substrate complementary to the active site. Biochemistry 29: 10159-10171.

Herschlag D, Cech TR. 1990b. Catalysis of RNA cleavage by the Tetrahymena thermophila ribozyme. 2. Kinetic description of the reaction of an RNA substrate that forms a mismatch at the active site. Biochemistry 29: 10172-10180.

Hsieh J, Walker SC, Fierke CA, Engelke DR. 2009. Pre-tRNA turnover catalyzed by the yeast nuclear RNase P holoenzyme is limited by product release. RNA 15: 224-234.

Johnston WK, Unrau PJ, Lawrence MS, Glasner ME, Bartel DP. 2001. RNA-catalyzed RNA polymerization: accurate and general RNAtemplated primer extension. Science 292: 1319-1325.

Kiss MM, Ortoleva-Donnelly L, Beer NR, Warner J, Bailey CG, Colston BW, Rothberg JM, Link DR, Leamon JH. 2008. Highthroughput quantitative polymerase chain reaction in picoliter droplets. Anal Chem 80: 8975-8981.

Larkin MA, Blackshields G, Brown NP, Chenna R, McGettigan PA, McWilliam H, Valentin F, Wallace IM, Wilm A, Lopez R, et al. 2007. Clustal $\mathrm{W}$ and Clustal $\mathrm{X}$ version 2.0. Bioinformatics 23: 2947-2948.

Lawrence MS, Bartel DP. 2005. New ligase-derived RNA polymerase ribozymes. RNA 11: 1173-1180.

Lazarev D, Puskarz I, Breaker RR. 2003. Substrate specificity and reaction kinetics of an X-motif ribozyme. RNA 9: 688-697.

Link DR, Anna SL, Weitz DA, Stone HA. 2004. Geometrically mediated breakup of drops in microfluidic devices. Phys Rev Lett 92: 054503.

Mazutis L, Griffiths AD. 2009. Preparation of monodisperse emulsions by hydrodynamic size fractionation. Appl Phys Lett 95: 688-697.

Mazutis L, Araghi AF, Miller OJ, Baret JC, Frenz L, Janoshazi A, Taly V, Miller BJ, Hutchison JB, Link D, et al. 2009a. Droplet-based microfluidic systems for high-throughput single DNA molecule isothermal amplification and analysis. Anal Chem 81: 4813-4821.
Mazutis L, Baret JC, Treacy P, Skhiri Y, Araghi AF, Ryckelynck M, Taly V, Griffiths AD. 2009b. Multi-step microfluidic droplet processing: kinetic analysis of an in vitro translated enzyme. Lab Chip 9: 2902-2908.

Paegel BM, Joyce GF. 2010. Microfluidic compartmentalized directed evolution. Chem Biol 17: 717-724.

Pekin D, Skhiri Y, Baret JC, Le Corre D, Mazutis L, Salem CB, Millot F, El Harrak A, Hutchison JB, Larson JW, et al. 2011. Quantitative and sensitive detection of rare mutations using droplet-based microfluidics. Lab Chip 11: 2156-2166.

Romero-Lopez C, Diaz-Gonzalez R, Berzal-Herranz A. 2007. RNA selection and evolution in vitro: powerful techniques for the analysis and identification of new molecular tools. Biotechnol Biotechnol Equip 21: 272-282.

Shih I, Been MD. 2000. Kinetic scheme for intermolecular RNA cleavage by a ribozyme derived from hepatitis delta virus RNA. Biochemistry 39: 9055-9066.

Siegel AC, Bruzewicz DA, Weibel DB, Whitesides GM. 2007. Microsolidics: fabrication of three-dimensional metallic microstructures in poly(dimethylsiloxane). Adv Mater 19: 727-733.

Stage-Zimmermann TK, Uhlenbeck OC. 1998. Hammerhead ribozyme kinetics. RNA 4: 875-889.

Stoltenburg R, Reinemann C, Strehlitz B. 2007. SELEX - a (r)evolutionary method to generate high-affinity nucleic acid ligands. Biomol Eng 24: 381-403.

Tang J, Breaker RR. 2000. Structural diversity of self-cleaving ribozymes. Proc Natl Acad Sci 97: 5784-5789.

Tawfik DS, Griffiths AD. 1998. Man-made cell-like compartments for molecular evolution. Nat Biotechnol 16: 652-656.

Tuerk C, Gold L. 1990. Systematic evolution of ligands by exponential enrichment: RNA ligands to bacteriophage T4 DNA polymerase. Science 249: 505-510.

Wanninayake U, Walker KD. 2012. Assessing the deamination rate of a covalent aminomutase adduct by burst phase analysis. Biochemistry 51: 5226-5228.

Wochner A, Attwater J, Coulson A, Holliger P. 2011. Ribozyme-catalyzed transcription of an active ribozyme. Science 332: 209-212.

Xia YN, Whitesides GM. 1998. Soft lithography. Annu Rev Mater Sci 28: 153-184.

Young B, Herschlag D, Cech TR. 1991. Mutations in a nonconserved sequence of the Tetrahymena ribozyme increase activity and specificity. Cell 67: 1007-1019.

Zaccolo M, Williams DM, Brown DM, Gherardi E. 1996. An approach to random mutagenesis of DNA using mixtures of triphosphate derivatives of nucleoside analogues. J Mol Biol 255: 589-603. 

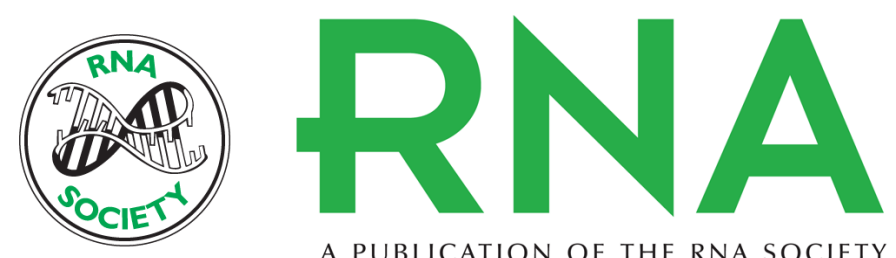

A PUBLICATION OF THE RNA SOCIETY

\section{Using droplet-based microfluidics to improve the catalytic properties of RNA under multiple-turnover conditions}

Michael Ryckelynck, Stéphanie Baudrey, Christian Rick, et al.

RNA 2015 21: 458-469 originally published online January 20, 2015

Access the most recent version at doi:10.1261/rna.048033.114

\section{Supplemental http://rnajournal.cshlp.org/content/suppl/2015/01/07/rna.048033.114.DC1 \\ Material}

References This article cites 45 articles, 12 of which can be accessed free at: http://rnajournal.cshlp.org/content/21/3/458.full.html\#ref-list-1

Open Access Freely available online through the RNA Open Access option.

Creative This article, published in $R N A$, is available under a Creative Commons License Commons (Attribution-NonCommercial 4.0 International), as described at License http://creativecommons.org/licenses/by-nc/4.0/.

Email Alerting Receive free email alerts when new articles cite this article - sign up in the box at the Service top right corner of the article or click here.

To subscribe to $R N A$ go to:

http://rnajournal.cshlp.org/subscriptions 